\title{
HISTÓRIA DA INSTITUCIONALIZAÇÃO DOS DIREITOS SOCIAIS: PRINCÍPIOS E CONCEITOS
}

\author{
Margarita Victoria Rodríguez ${ }^{1}$
}

\begin{abstract}
RESUMO
O artigo é o resultado da pesquisa que analisa historicamente o conceito e a materialização das políticas sociais na sociedade capitalista na América Latina, mais especificamente as políticas educacionais e o papel do Estado como o seu indutor. As fontes documentais são as Constituições Nacionais promulgadas durante o século XX no México, na Colômbia, na Venezuela e no Brasil. O texto também discorre acerca dos alcances e limites das políticas educacionais como instrumentos de consolidação dos direitos sociais. As definições constitucionais e as políticas educacionais sintetizam as tensões e as lutas sociais travadas nos diferentes momentos históricos, com vistas à efetivação dos direitos humanos.
\end{abstract}

Palavras-chave: Direitos Sociais; Política Educacional; Constituições Nacionais.

\section{HISTORY OF INSTITUTIONALIZATION OF SOCIAL RIGHTS: PRINCIPLES AND CONCEPTS}

\begin{abstract}
The paper is the result of research that analyzes historically the concept and the materialization of social policies in capitalist societies in Latin America, more specifically the education policies and the role of the State as their promoter. The documents surveyed include the National Constitutions promulgated during the 20th century in Mexico, Colombia, Venezuela and Brazil. The text also points out the scope and the limits of education policies as instruments of consolidation of social rights. The constitutional definitions and the education policies summarize the tensions and the social struggles in different historical moments, aimed at effectuating human rights.
\end{abstract}

Keywords: Social Rights; Education policy; National Constitutions. 
O artigo tem como objetivo analisar o processo histórico de instalação do conceito e a materialização das políticas sociais na sociedade capitalista, no contexto latinoamericano, mais especificamente as políticas educacionais e o papel do Estado como o seu indutor. As fontes documentais consultadas são as Constituições Nacionais promulgadas durante as primeiras décadas do século XX no México, na Colômbia, na Venezuela e o no Brasil. O texto também discorre a respeito dos alcances e limites das políticas sociais como instrumento de consolidação dos direitos sociais. Em consequência, as políticas educacionais vinculam-se ao papel do Estado e às definições constitucionais, à medida que sintetizam as tensões e as lutas sociais que têm como objetivo o cumprimento dos direitos humanos.

\section{Origem e objetivos das políticas sociais.}

A seguir, discutimos as origens históricas das políticas sociais, no contexto da sociedade capitalista. Os conceitos de política social e política educacional foram construídos historicamente. Saviani (1998) explica que a política social tem como objetivo compensar o caráter antissocial da economia que caracteriza essa sociedade.

Para entender o processo de institucionalização dos direitos políticos e sociais, é imprescindível distinguir dois conceitos básicos: sociedade civil e sociedade política. Segundo Bobbio (1982), são conceitos que têm adquirido diversos significados ao longo do tempo. Neste texto, será adotada a concepção marxista.

Segundo Marx (2005), a sociedade civil é a esfera do homem vivo e ativo, dentro da qual desenvolve os seus interesses individuais, correspondentes ao contexto individual. Por tal motivo, essa esfera se converte no espaço onde se materializam os antagonismos concretos de classes.

O Estado, para o autor, representa apenas a esfera burocrática, mediante a qual o homem se torna membro de uma comunidade administrada, portanto, basicamente alheia. Assim, o Estado é um aparelho a serviço da sociedade burguesa, que emergiu como consequência da Revolução Francesa. Caracteriza-se como uma organização social dual, dividida, por um lado, pela existência das pessoas reais, individuais, e por outro, pela vida política, que se dá no Estado. Desse modo, a primeira asseveração consiste em formular que o objeto de estudo da política educativa é entender o Estado como o aparelho a serviço da sociedade burguesa.

Entretanto, Gramsci (1980, p. 177) estipula que sociedade civil é “[...] o conjunto dos organismos vulgarmente chamados privados [...] que correspondem à função de hegemonia que o grupo dominante exerce em toda a sociedade". Para o autor, a sociedade civil está constituída por determinadas superestruturas, tais como sindicatos, partidos, escolas, imprensa, igreja, que não são controladas pelo Estado. Trata-se de um conceito de caráter cultural. Nesses espaços de atuação e ação, todos os indivíduos participam da organização da sociedade; são organismos privados, que se diferenciam das funções da esfera pública da sociedade política.

A "sociedade política" é o Estado-Governo, ou seja, o aparelho governamental que funciona mediante leis e conta com um aparelho de controle social que regula as relações sociais de produção, exercendo a condução dos meios de comunicação de massas, educação e hierarquia eclesiástica. Segundo Gramsci (1980), o conceito de Estado não se reduz apenas ao governo, porque o Estado envolve a "sociedade política", que exerce a força (a esfera das instituições políticas e o controle e organização legal e constitucional) e a "sociedade civil", que exerce o consentimento (esfera privada ou não estatal e econômica). 
Enfim, na categoria "sociedade civil", Gramsci (1980) elenca uma multiplicidade de organismos denominados vulgarmente como privados (escolas, igrejas e órgãos de imprensa) que cumprem uma função de hegemonia cultural e política que a classe dominante exerce sobre toda a sociedade. Por esse motivo, o conceito de Estado é complexo: na noção geral de Estado entram elementos que devem ser referidos à sociedade civil (pode-se indicar, a esse respeito, que Estado = sociedade política + sociedade civil, o que equivale dizer, hegemonia revestida de coerção).

Dado que as políticas sociais, e mais especificamente as políticas educativas, são definidas no interior do Estado e a sociedade civil organizada participa do processo de definição por intermédio dos seus representantes, o papel do científico social é precisamente desvendar e compreender o processo e as lutas que se travam no aparelho do Estado, e verificar em que medida os interesses dos diferentes estamentos da sociedade são contraditórios.

Portanto, são diversas as fontes que os investigadores costumam empregar para apreender os mecanismos de promulgação da legislação e tomada de decisões a respeito das políticas educativas. Frequentemente, os documentos oficiais que normatizam as medidas políticas - leis, decretos, resoluções, entre outros - são parte do universo dos estudos acadêmicos. Porém não são suficientes para explicitar a complexidade das políticas educativas. Tampouco a promulgação de uma norma implica a implementação de uma determinada política educativa. Por este motivo, é recomendável a utilização de diversas fontes e agentes de informação, tanto públicos como privados, entre os quais se destacam dados estadísticos, notícias e colunas de diários, declarações de administradores ou indivíduos que atuam no sistema de ensino, e material fílmico.

Entretanto, salientamos que os documentos oficiais registram as decisões e, de certa forma, explicitam os consensos e os acordos políticos da classe dirigente, no núcleo do Estado, expressando as contradições e os antagonismos da dinâmica social: "[...] o Estado é todo o complexo de atividades práticas e teóricas com as quais a classe dirigente não somente mantém e justifica o seu domínio, senão também obtém o consenso ativo dos governantes". (GRAMSCI, 1980, p. 96).

O conteúdo da política social e da política educacional reporta-nos ao termo política, derivado

[...] do adjetivo originado de pólis (politikós), que significa tudo o que se refere à cidade e, conseqüentemente, o que é urbano, civil, público, e até mesmo sociável e social. $\mathrm{O}$ termo Política se expandiu graças à influência da grande obra de Aristóteles, intitulada Política, a qual deve ser considerada o primeiro tratado sobre a natureza, funções e divisão do Estado, além de referir-se às várias formas de Governo, com a significação mais comum de arte ou ciência do Governo. [...] Na época moderna, o termo perdeu seu significado original, substituído pouco a pouco por outras expressões como "ciência do Estado", "doutrina do Estado", "ciência política", "filosofia política", etc., passando a ser comumente usado para indicar a atividade ou conjunto de atividades que, de alguma maneira, têm como termo de referência a polís, ou seja, o Estado.” (BOBBIO, N.; MATTEUCCI, N.; PASQINO, G., 2000, p. 954).

Como notamos na definição clássica de política, o termo está relacionado às questões da cidade, ou seja, ao urbano, público e civil, isto é, à polis ${ }^{2}$. A primeira obra que trata da temática é "A Política", escrita por Aristóteles, que discute o Estado e as diversas formas de governo. Posteriormente, o termo política faz alusão a um campo de estudo que 
se dedica à análise das atividades humanas articuladas "às coisas do Estado", fazendo referência ao conjunto de ações atribuídas ao Estado moderno ou que emanam dele (SHIROMA, MORAES e EVANGELISTA, 2002).

Porém, o caráter social da política é uma das conquistas do século XX, com a ampliação da noção de Direitos do Homem que herdamos do Iluminismo. Quando comparamos os documentos da Declaração dos Direitos do Homem e do Cidadão, da Revolução Francesa de 1789, e a Declaração Universal dos Direitos Humanos, da Organização das Nações Unidas (ONU), de 1948, percebemos a ampliação do reconhecimento dos direitos que devem ser garantidos a cada ser humano (Cf. ONU, 1948 e FAURÉ, 1996).

No Documento da ONU de 1948, o Direito à Educação é reconhecido nos seguintes termos: "I. Todo ser humano tem direito à educação. A educação deve ser gratuita, ao menos nos estágios elementar e fundamental. A educação elementar deve ser compulsória [...]." (ONU, 1948, art. 26)

Thomas Humphrey Marshall (1967) explica que o conceito de cidadania pode ser dividido em três elementos - civil, político e social - e cada um deles se consolida historicamente. O século XVIII foi o século dos direitos civis. Eles surgiram no contexto do movimento de lutas políticas e sociais desencadeadas durante a Revolução Francesa contra o absolutismo dos monarcas. São os direitos que embasam a concepção liberal clássica. São de caráter civil e determinam que o Estado deve respeitar os direitos fundamentais do ser humano; correspondem aos direitos individuais de liberdade, igualdade, propriedade, segurança, direito à vida, entre outros.

Os direitos políticos foram conquistados pela sociedade no século XIX. Asseguram ao cidadão o direito de livre associação e reunião, de participar tanto de organizações políticas como sindicais, de desempenhar atividades políticas e eleitorais, do sufrágio universal, entre outros. São denominados direitos individuais e também pertencem à tradição da ideologia liberal.

No século XX, emergiram os direitos sociais, tidos como direitos de terceira geração, junto com os direitos econômicos ou do crédito. Foram conquistados a partir da luta e da mobilização política dos operários e sindicatos, por melhores condições de vida para os membros da sociedade. Desse modo, ampliou-se a responsabilidade do Estado, que deve satisfazer as necessidades dos indivíduos e prestar serviços que atendam às demandas coletivas.

Entre os direitos sociais, realçamos o direito à educação, que surgiu entre os diversos direitos sociais propagados e efetivados no século passado. A questão de que o direito à educação seja detalhado e especificado nas Cartas Magnas dos países da América Latina promulgadas nos anos 1980 e 1990 manifesta um salto qualitativo com relação às constituições anteriores. Isso porque, à medida que se especificaram os princípios, objetivos, preceitos, organização dos sistemas e financiamento da educação, se assentaram as bases que fundamentaram os instrumentos jurídicos para a sua garantia.

Situar o direito à educação dentro dos direitos sociais significa colocá-lo em destaque e conceder-lhe primazia. A dimensão que o direito à educação alcança no âmbito dos direitos humanos ou indispensáveis nos conduz a verificar em que medida esses direitos educativos são materializados e a compreender que o Estado, no contexto da sociedade capitalista, é responsável por garantir o acesso à educação da qualidade social, mediante a organização de um sistema educativo que seja capaz de formar ao homem e prepará-lo para o exercício consciente da cidadania. 


\section{Constituições latino-americanas do século XX e os direitos sociais}

A Constituição Política dos Estados Unidos Mexicanos de 1917 foi primeira Carta Magna que incluiu os direitos sociais. Ela foi o resultado de uma longa luta, iniciada em 1910, na qual os movimentos sociais de trabalhadores e camponeses visavam a derrubar o regime autoritário e conservador instaurado por José de la Cruz Porfirio Díaz Mory ${ }^{3}$.

Observamos que muitas das lideranças revolucionárias eram militares e políticos descontentes que pertenciam aos grupos políticos opositores. Outrossim, os líderes acabaram fortalecendo os interesses das elites tradicionais e lentamente, no decorrer do processo pós-revolucionário, foram abandonadas as bandeiras que haviam justificado as revoltas populares. Alguns historiadores, como Gonzalez (2007), questionam o movimento e opinam que não existiu tal revolução, porque se mantiveram os privilégios das frações da classe dominante tradicional pertencente ao setor agrário. O povo mexicano continuou imerso na injustiça social. (MASON, 1997).

O movimento foi o resultado de várias causas. Sob o ponto de vista político, o regime estava envelhecido; os novos dirigentes não tinham espaço no cerne do poder e pressionavam para obter o controle do aparelho estatal (GONZALEZ, 2007). Socialmente, a sociedade encontrava-se insatisfeita, dada à má gestão administrativa e à falta de justiça social, como consequência da concentração da renda e do poder político nas mãos de poucas famílias tradicionais.

A população, em geral, vivia em condições de extrema pobreza. Os camponeses eram explorados e experimentavam situações de indigência. Eram objetos de maus-tratos e de relações de trabalho servis, pois as terras estavam sob o controle dos fazendeiros. Os operários fabris enfrentavam longas jornadas de trabalho e recebiam salários miseráveis, que não eram suficientes para sustentar as suas famílias. (ELIZAGA, 1996).

Sob o ponto de vista cultural, o país havia adotado uma concepção francesa que ignorava a cultura nacional. Não se respeitavam os valores e os costumes locais e muito menos a cultura dos povos originários, que era praticada por grande parte da sociedade. $\mathrm{O}$ governo de José de la Cruz Porfirio Díaz Mory não conseguia compreender a indispensabilidade de mudar essa realidade e propiciar as condições de justiça social e participação política essenciais para ir ao encontro das demandas da sociedade civil.

Apesar das críticas a esse movimento e dos mitos que rodeiam o processo revolucionário desse país, ressaltamos que, durante o século XX, o México experimentou profundas revoltas populares que influenciaram a vida política e cultural da sociedade. Foi a primeira nação do mundo a gestar grandes movimentos sociais reivindicatórios e de contestação à ordem vigente. Essas manifestações das massas operárias e camponesas mexicanas influenciaram as lutas dos cidadãos de outros países por melhores condições de vida e trabalho, e ainda servem de referências para muitas das causas populares em defesa dos direitos sociais. (HART, 1990).

O capítulo I da Constituição mexicana de 1917 trata dos Direitos Individuais e suas garantias. Destina 27 artigos para assegurar diversos direitos políticos e sociais, entre os quais se distingue a liberdade do ensino. Determina-se que o ensino primário será gratuito, obrigatório e laico. 
Art. $3^{\circ} \mathrm{O}$ ensino é livre; mas será laico aquele que se der nos estabelecimentos oficiais de educação, assim como o ensino primário, elementar e superior que se ofereça nos estabelecimentos particulares.

Nenhuma corporação religiosa e nem ministro de algum culto poderão estabelecer ou dirigir escolas de instrução primária.

As escolas primárias particulares só poderão se estabelecer sujeitando-se à vigilância oficial.

Nos estabelecimentos oficiais, se oferecerá gratuitamente o ensino primário (MÉXICO, 1917, tradução da autora).

Como vemos, a Constituição mexicana segue os princípios da visão tradicional liberal a respeito da educação, proclamados no século XVIII, durante a revolução francesa.

No artigo $5^{\circ}$, a Constituição fixa especificamente a proteção dos trabalhadores. Garante os contratos de trabalhos remunerados, evitando-se qualquer tipo de exploração humana:

Art. $5^{\circ}$ Ninguém poderá ser obrigado a realizar trabalhos pessoais sem a justa retribuição e sem seu pleno consentimento, [...].

O Estado não pode permitir que se leve a efeito nenhum contrato, pacto ou convênio que tenha por objeto o menoscabo, a perda ou o irrevocável sacrifício da liberdade do homem, seja por causa de trabalho, de educação ou de voto religioso. [...]

O contrato de trabalho só obrigará a prestar o serviço conveniado pelo tempo que fixe a lei, sem poder exceder um ano em prejuízo do trabalhador, e não poderá estender-se, em nenhum caso, à renúncia, perda ou menoscabo de qualquer dos direitos políticos ou civis. [...] (MÉXICO, 1917, tradução da autora)

Ainda a Constituição de 1917 destina o Título VI para legislar a respeito dos Direitos do Trabalho e Previdência Social, entre os quais: jornada de trabalho de 8 horas; proteção do trabalho infantil, das mulheres e dos jovens; igualdade de direitos entre homens e mulheres; garantias sociais, para as trabalhadoras grávidas e que tiveram filhos, de manter os seus salários e empregos; jornada com descanso remunerado; garantias de salubridade no trabalho; salário mínimo; participação dos trabalhadores nos ganhos das empresas; e direito à greve.

A Constituição institui a reforma agrária mediante a devida distribuição das terras. Estabelecem-se garantias para a permanência dos pequenos produtores no campo. $\mathrm{O}$ artigo 27 determina:

A Nação terá, o tempo todo, o direito de impor à propriedade privada as modalidades que dite o interesse público, assim como o de regular o aproveitamento dos elementos naturais suscetíveis de apropriação, para fazer uma distribuição equitativa da riqueza pública, cuidar de sua conservação, alcançar o desenvolvimento equilibrado do país e o melhoramento das condições de vida da população rural e urbana. Em consequência, se ditarão as medidas necessárias para ordenar os assentamentos humanos e estabelecer as adequadas provisões, usos, reservas e destinos de terras, águas e bosques, a fim de executar obras públicas e de planejar e regular a fundação, conservação, melhoramento e crescimento dos centros populacionais; para preservar e restaurar o equilíbrio ecológico; para o fracionamento dos latifúndios; para dispor, nos termos da lei regulamentar, a organização e a exploração coletiva dos 
terrenos baldios e comunidades; para o desenvolvimento da pequena propriedade agrícola; para a criação de novos centros de população agrícola com as terras e as águas que lhes sejam indispensáveis; para o fomento da agricultura e para evitar a destruição dos elementos naturais e os danos que a propriedade possa sofrer em prejuízo da sociedade. Os núcleos populacionais que careçam de terras e águas, ou não as tenham em quantidade suficiente para as necessidades da sua população, terão o direito a que se lhes dote, tomando-as das propriedades imediatas, respeitando sempre a pequena propriedade agrícola. (MÉXICO, 1917, tradução da autora).

Os legisladores, como percebemos, tentaram atenuar o descontentamento nacional no tocante à falta de justiça social, especialmente na área rural. No entanto, essas medidas reformistas não romperam com as relações de dominação capitalista, fundada na distribuição e na apropriação desiguais dos bens materiais.

Posteriormente, muitas das reformas constitucionais promulgadas nos países da América Latina, no século XX, introduziram os direitos sociais inspirados tanto na Constituição mexicana (1917) como na Constituição alemã de Weimar (1919).

Desse modo, por exemplo, a Constituição colombiana de 1936 incorporou alguns dos direitos sociais de proteção aos trabalhadores, assistência e seguridade social, educação primária gratuita, e saúde pública a cargo do Estado.

$\mathrm{Na}$ Alemanha, esses diretos surgiram como consequência do processo de urbanização e industrialização iniciado na segunda metade do século XIX. Esse contexto de mudanças econômicas fortaleceu o movimento operário urbano e originou o aumento de novos trabalhadores que se incorporaram às indústrias, em condições de total falta de garantias de higiene, saúde e segurança social e trabalhista. Os trabalhadores participavam de diversos movimentos políticos cujas ideologias estavam influenciadas por concepções comunistas, socialistas, sindicalistas e social-democratas.

De acordo com Arenas Monsalve (2009), o novo movimento operariado alemão contribuiu para a instalação de associações e sindicatos para defender seus direitos. Além disso, foi criado o Partido Social-democrata, que previa, na sua plataforma política, a proteção dos direitos sociais dos operários, como uma forma de garantir e controlar essas demandas trabalhistas, bem como de proteger a força de trabalho e assegurar a produtividade das empresas.

O texto da Constituição colombiana de 1936 incorpora algumas das propostas da Constituição alemã, especialmente no que tange à educação e à proteção social. A Colômbia dos anos 1930 iniciou um processo de estruturação do Estado em termos de políticas sociais, com vistas a se insertar de forma ativa no novo estágio de produção do capitalismo mundial. Porém, o país contava ainda com poucas leis que regulamentavam o trabalho assalariado. E como os demais países latino-americanos, criou, de forma paulatina, as condições basilares para elaborar as normas legais para satisfazer as novas demandas do capital, além de criar mecanismos para proteger a massa de trabalhadores mediante um Estado que se preocupava com o bem-estar social.

No artigo 14, a Constituição colombiana menciona a liberdade do ensino. Estabelece a gratuidade e a obrigatoriedade do ensino fundamental oferecido nas escolas do Estado.

Quanto à segurança social, o artigo 16 determina que o Estado é responsável pela assistência pública, de forma a subsidiar as pessoas que, por diversas razões físicas, estejam incapacitadas. Portanto, não se trata de um direito universal que abarca todos os 
colombianos, independentemente de sua condição de saúde. Ainda se mantém um enfoque social baseado no princípio da caridade:

Art. 16. A assistência pública é função do Estado. Deverá ser prestada às pessoas que, carecendo de meios de subsistência e de direito para exigi-la de outras pessoas, estejam fisicamente incapacitadas para o trabalho. (COLOMBIA, 1936, tradução da autora).

A questão trabalhista apresenta-se em termos de proteção estatal, embora não se detalhem as condições desse direito social. No artigo 17, a Constituição estabelece que "O trabalho é una obrigação social e gozará de especial proteção do Estado". Como constatamos, a Constituição de 1936 não esclarece quais são os direitos ou as garantias dos trabalhadores, como no caso das Constituições alemã e mexicana. A questão laboral reveste-se em termos de proteção estatal, mas não se explicitam as condições desse direito social.

A reforma constitucional de 1936, de certa forma, incorporou os princípios e os preceitos dos movimentos políticos e ideológicos europeus e americanos, em especial o alemão, que estava marcado pela proteção dos direitos sociais de índole assistencial, como o caso da saúde, apesar das condições históricas diferenciadas do contexto latinoamericano e da sua relação de dependência econômica e cultural com os países capitalistas centrais. A Colômbia não era alheia às crises da sociedade capitalista naquele momento. Também adotou políticas sociais para amenizar os efeitos negativos das crises econômicas.

Porém, somente nos anos 1960 houve uma mudança substancial de caráter conceitual nas políticas públicas. O Decreto n. 3224/1963 reorganizou o Ministério de Saúde Pública, superando o conceito de política social entendida como caridade. Instalavase a concepção de assistência pública vinculada aos serviços sociais, destinados às camadas sociais consideradas vulneráveis. Essa ação estatal era considerada como a garantia do cumprimento dos direitos do cidadão. Por fim, definitivamente a Constituição de 1991 incorporou a proteção social como direito, conforme havia sido consagrada na Constituição alemã. (OLIVA, 2010).

Na Constituição de 1991, o artigo 11 estabelece o direito à vida para todos os colombianos. O Capítulo 2, denominado dos Direitos Sociais, Econômicos e Culturais, preconiza a igualdade de direitos e oportunidades entre o homem e a mulher (Art. 43). Também fixa a proteção do Estado durante e após a gravidez, e prevê subsídio alimentar estatal para as mulheres desempregadas ou sem família.

$\mathrm{O}$ artigo 44 estipula os direitos fundamentais das crianças, entre os quais aparecem a educação e a cultura, bem como a recreação e o desenvolvimento intelectual, físico e emocional autônomo. No artigo 48, considera-se a Seguridade Social como um serviço público obrigatório e determina-se que o Estado é responsável por sua coordenação e controle. Esse artigo inclui a incorporação do legado alemão e latino-americano do século XX a respeito das ações de cunho social por parte do poder público e do papel do Estado como promotor e indutor de políticas de bem-estar social.

O artigo 49 estipula que o Estado é responsável por garantir o direito à saúde: "A atenção à saúde e o saneamento ambiental são serviços públicos a cargo do Estado. Garante-se a todas a pessoas o acesso aos serviços de promoção, proteção e recuperação da saúde." (COLÔMBIA, 1991, tradução da autora).

A Constituição de 1991 confirma, ainda, o direito a uma moradia digna, ao lazer, e ao exercício dos esportes. Da mesma forma, também se ocupa de fixar os direitos trabalhistas, como salário mínimo, estabilidade no emprego, e qualidade no trabalho, entre outros: 
Art. 53. O Congresso expedirá o estatuto do trabalho. A Lei terá em conta pelo menos os seguintes princípios mínimos fundamentais: Igualdade de oportunidades para todos os trabalhadores; remuneração mínima vital e móbil, proporcional à quantidade e à qualidade de trabalho; estabilidade no emprego, sem renúncia dos benefícios mínimos estabelecidos em normas trabalhistas; [...] garantia de segurança social, capacitação, treinamento e descanso necessário; proteção especial da mulher, da maternidade e do menor trabalhador. (COLÔMBIA, 1991, tradução da autora).

O processo de incorporação dos direitos sociais de forma abrangente na tradição constitucionalista colombiana concretizou-se no final do século XX, embora, desde os anos 1930, houvesse no país um amplo debate sobre o tema.

A Venezuela, da mesma forma que outros países latino-americanos, mediante a promulgação da Constituição dos Estados Unidos da Venezuela, em 1936, resgatou a tradição social-democrata, frisando a total rejeição às concepções socialistas e comunistas, e expressando claramente a tensão política daquele momento. Após a morte do presidente Juan Vicente Gómez (1931-1935), em dezembro de 1935, a nação, que havia sofrido sob os desígnios de uma das mais duras ditaduras, novamente enfrentou disputas e enfrentamentos entre as frações da classe dominante. Os familiares de Gomez pretendiam impor outro presidente, mas Elezar López Contreras (1936-1941), então Ministro da Guerra, terminou o mandado de Gómez em abril de 1936. Também finalizou o longo período caracterizado pelas lideranças caudilhistas, e começou o processo de transição democrática. Contreras foi eleito como presidente para o período de 1936-1941, e imediatamente propôs a reforma constitucional, encurtando o prazo de mandato do presidente da república de sete para cinco anos.

Assim, em 1936, durante o governo democrático, foi aprovada a nova constituição, que, entretanto, ainda mantinha elementos do conservadorismo do período anterior, ao rejeitar, no artigo 32, as doutrinas políticas de cunho anarquista ou comunista: "Consideram-se contrárias à independência, à forma política e à paz social da Nação as doutrinas comunista e anarquista. Os que as proclamarem, propagarem ou praticarem serão considerados traidores da Pátria e castigados conforme as leis" (VENEZUELA, 1936, tradução da autora). Essa determinação foi suprimida na Reforma Constitucional de 1945.

Apesar da sua vinculação com o regime autoritário, o presidente Contreras implementou uma política de governo que promoveu as relações democráticas, de modo que a Constituição de 1936 assegura a liberdade de expressão e permite a existência de partidos e sindicatos. Institui os direitos sociais de proteção aos trabalhadores e garante a instalação da seguridade social no país.

Com relação à proteção da força de trabalho, no artigo 32 a Constituição confirma os direitos trabalhista modernos e prevê a promulgação de futuras normas legais que fixem benefícios tais como tempo para o descanso, férias remuneradas e formação técnica para os trabalhadores: 
A lei estabelecerá o necessário para a maior eficácia e estímulo ao trabalho, organizando-o adequadamente e estabelecendo a proteção especial que deverá se destinar aos operários e trabalhadores, para prover o melhoramento de sua condição física, moral e intelectual, e o incremento da população.

[...]

A legislação do trabalho observará os seguintes preceitos, além de outros que contribuam para melhorar as condições do operário ou trabalhador:

1. Repouso semanal, de preferência aos domingos;

2. Férias anuais remuneradas;

Para os efeitos desses preceitos, não se distinguirá entre o trabalho manual e o intelectual ou técnico;

3. A Nação fomentará o ensino técnico dos operários. (VENEZUELA, 1936, tradução da autora).

No que diz respeito ao direito à educação, a Constituição de 1936 estabelece a liberdade do ensino, bem como a obrigatoriedade da educação moral e cívica, que deve "[...] se inspirar no engrandecimento nacional e na solidariedade humana. Haverá não menos que uma escola em toda a localidade cuja população escolar não seja menor de trinta alunos" (VENEZUELA, 1936, tradução da autora).

No final dos anos 1950, o país vivenciou mudanças políticas e econômicas. O processo democrático que havia sido instaurado em 1958 instituiu políticas de cunho nacionalista, como na área petrolífera: não foram permitidas concessões de exploração às empresas multinacionais. Foi constituída a Corporação Venezuelana de Petróleo e em 1960, por iniciativa do Ministro de Energia e Minas Juan Pablo Pérez Alfonzo, criou-se a Organização dos Países Exportadores de Petróleo (OPEP). Também se desencadeou o processo da Reforma Agrária e, em 1961, promulgou-se uma nova Constituição.

Mas o contexto democrático era muito frágil, sob o ponto de vista da governança e do controle político. O presidente Rómulo Ernesto Betancourt Bello (1959-964) enfrentou vários incidentes e revoltas políticas, entre as quais a tentativa de atentado organizado pelo ditador da República Dominicana Rafael Leónidas Trujillo.

Além disso, os grupos de esquerda que não faziam parte do governo e que foram excluídos do Pacto social e político instaurado na época organizaram um movimento armado, que recebeu o nome de Forças Armadas da Libertação Nacional, que contava com o apoio do Partido Comunista e de Fidel Castro. No ano 1962, organizaram o levantamento insurrecto em Capúrano e Puerto Caballero que procurava desestabilizar as forças armadas, mas não tiveram sucesso.

Nesse contexto conflitivo, a Constituição de 1961, na parte introdutória, explicita os princípios do caráter social e estabelece:

[...] proteger e enaltecer o trabalho, amparar a dignidade humana, promover o bem geral e a segurança social; lograr a participação equitativa de todos no desfrute da riqueza, segundo os princípios da justiça social, e fomentar o desenvolvimento da economia ao serviço do homem; manter a igualdade social e jurídica, sem discriminações derivadas de raça, sexo, credo ou condição social [...] (VENEZUELA, 1961, tradução da autora). 
Essa Constituição incorpora os elementos constitutivos do bem-estar social que caracterizaram as políticas públicas do Estado liberal, social e democrático que se configurou durante o século XX, tanto na Europa como na América Latina.

No Capítulo IV, denominado Direitos Sociais, o artigo 73 dispõe que o Estado deverá proteger a família e assegurar a aquisição de moradia adequada e higiênica. $\mathrm{O}$ artigo 74 assegura os direitos femininos de proteção tanto da gravidez quanto do nascimento da criança em condições de proteção material e moral. Além disso, o artigo 76 garante o direito à saúde, entendida como um serviço público de prevenção humana:

Art. 76. Todos têm direito à proteção da saúde. As autoridades velarão pela manutenção da saúde pública e proverão os meios de prevenção e assistência a quem careça deles. Todos estão obrigados a se submeter às medidas sanitárias que estabeleça a lei, dentro dos limites impostos pelo respeito à pessoa humana (VENEZUELA, 1961, tradução da autora).

Tanto a Constituição de 1961 como a Constituição de 1936 firmam os direitos dos trabalhadores, tais como: jornada de oito horas, descanso semanal, salário mínimo, férias, participação dos trabalhadores nos lucros das empresas, entre outros:

Art. 87. A lei proverá os meios conducentes à obtenção de um salário justo; estabelecerá normas para assegurar a todo trabalhador pelo menos um salário mínimo; garantirá igual salário para igual trabalho, sem qualquer discriminação; fixará a participação que deve corresponder aos trabalhadores nos benefícios das empresas; e protegerá o salário e as prestações sociais de embargo, na proporção e nos casos que se fixem e com os demais privilégios e garantias que ela mesma estabeleça. (VENEZUELA, 1961, tradução da autora).

Os artigos 88, 89 e 90 fixam outras conquistas dos trabalhadores referentes à seguridade social: plano de proteção para assegurar o pagamento de benefícios por antiguidade, promoção da estabilidade no emprego e mecanismos de amparo de possíveis demitidos, bem como negociação coletiva. O artigo 94 prevê a instalação de um sistema de seguridade social para todos os habitantes do país que promova a proteção da vida humana de forma maciça:

Art. 94. Em forma progressiva, será desenvolvido um sistema de segurança social para proteger todos os habitantes da República contra infortúnios do trabalho, doença, invalidez, velhice, morte, desemprego e quaisquer outros riscos que possam ser objeto de previdência social, assim como contra as cargas derivadas da vida familiar.

Aqueles que careçam de meios econômicos e não estejam em condições de procurá-los terão direito à assistência social, por isso devem ser incorporados ao sistema de segurança social (VENEZUELA, 1961, tradução da autora).

No que tange ao direito à educação a Constituição de 1961 estabelece a sua gratuidade nos estabelecimentos oficiais em todos os níveis do ensino. No artigo 78, fixa a obrigação do Estado de sustentar e criar escolas para assegurar o acesso dos habitantes à educação e à cultura: 
Art. 78. Todos têm direito à educação. O Estado criará e sustentará escolas, instituições e serviços suficientemente dotados para assegurar o acesso à educação e à cultura, sem mais limitações que as derivadas da vocação e das aptidões.

A educação oferecida pelos institutos oficiais será gratuita em todos seus ciclos. Não obstante, a lei poderá estabelecer exceções a respeito do ensino superior e especial, quando se tratar de pessoas que possuem fortuna (VENEZUELA, 1961, tradução da autora).

Esses antecedentes constitucionais serviram de marco legal para a promulgação da nova Constituição da República Bolivariana da Venezuela em 1999 (VENEZUELA, 1999), considerada uma das Cartas Magnas de América Latina que detalha e assegura mais especificamente os direitos sociais e salienta o papel do Estado como responsável por promover a justiça social, econômica e política dos cidadãos.

No Brasil, apesar de que os direitos sociais, especialmente os vinculados às relações trabalhistas, educação e saúde, já haviam sido tratados nas Constituições promulgadas a partir dos anos 1930, a Constituição de 1988 consagra definitivamente os direitos sociais no Capítulo II (Dos Direitos e Garantias Fundamentais) e no Capítulo VIII (Da Ordem Social), ao incluir os seguintes direitos: educação, saúde, alimentação, trabalho, moradia, ócio, segurança, previdência social, proteção à maternidade e à infância, assistência aos desamparados $\left(\right.$ Art. $6^{\circ}$ ). Destina vários artigos - do $7^{\circ}$ ao $11^{\circ}-$ aos direitos sociais dos trabalhadores.

Na legislação brasileira, detectamos que, historicamente, o direito à educação tem sido incorporado constitucionalmente, a partir de 1934, mantendo-se na Constituição de 1946 e também na Constituição Ditatorial de 1967 e na sua emenda de 1969.

A seguir, elencamos os textos constitucionais brasileiros nos quais fica expresso o direito à educação: a Constituição de 1934, no artigo 149, estabelece que a educação é direito de todos; no artigo 150, ressalta a obrigatoriedade e a gratuidade para o ensino primário de quatro anos:

Art. 149. A educação é direito de todos e deve ser ministrada pela família e pelos poderes públicos, cumprindo a estes proporcioná-la a brasileiros e a estrangeiros domiciliados no País, de modo que possibilite eficientes fatores de vida moral e econômica da Nação, e desenvolver num espírito brasileiro a consciência da solidariedade humana (BRASIL, 1934)

A Constituição de 1946, além de manter o princípio do direito à educação e da obrigatoriedade e gratuidade, também introduz o conceito de dever do Estado quanto ao direito à educação e à obrigatoriedade escolar (HORTA, 1998) e conserva o princípio de educação universal, ou seja, a educação entendida como direito de todos:

Art. 166. A educação é direito de todos e será dada no lar e na escola. Deve inspirar-se nos princípios de liberdade e nos ideais de solidariedade humana.

Art. 167. O ensino dos diferentes ramos será ministrado pelos Poderes Públicos e é livre à iniciativa particular, respeitadas as leis que o regulem (BRASIL, 1946)

A Constituição de 1967, promulgada pela ditadura cívico-militar, sofreu alterações mediante a Emenda Constitucional nº 1, em 1969. Porém, o princípio de direito à educação é mantido, e acrescenta ainda o dever do Estado: 
Art. 168. A educação é direito de todos e será dada no lar e na escola; assegurada a igualdade de oportunidade, deve inspirar-se no princípio da unidade nacional e nos ideais de liberdade e de solidariedade humana.

Emenda Constitucional de 1969: Art. 176. A educação, inspirada no princípio da unidade nacional e nos ideais de liberdade e solidariedade humana, é direito de todos e dever do Estado, e será dada no lar e na escola (BRASIL, 1967).

Somente na Constituição de 1988 o Direito à Educação aparece mais detalhado e explicitado, registrando-se até os mecanismos para a sua garantia. Nunca antes, na história da educação brasileira, havia sido especificado com tanta minúcia o direito à educação, constitucionalmente. A Constituição destina um capítulo específico para a educação, que significa um avanço com relação ao ensino obrigatório, porque reconhece, de modo prático, o direito público subjetivo, pois estabelece que o indivíduo que não tiver acesso ao ensino obrigatório possui mecanismos jurídicos para fazer valer esse direito. (CURY, 2000).

O Capítulo III da Constituição de 1988 trata da educação, da cultura e do esporte, na Seção I (Da Educação). O artigo $5^{\circ}$ fixa o direito à educação e o artigo 208 estabelece o dever do Estado em garantir a materialização desse direito:

Art. 205. A educação, direito de todos e dever do Estado e da família, será promovida e incentivada com a colaboração da sociedade, visando ao pleno desenvolvimento da pessoa, seu preparo para o exercício da cidadania e sua qualificação para o trabalho.

Art. 208. O dever do Estado com a educação será efetivado mediante a garantia de: I - ensino fundamental, obrigatório e gratuito, assegurada, inclusive, sua oferta gratuita para todos os que a ele não tiveram acesso na idade própria;

II - Progressiva universalização do ensino médio gratuito;

$\S 1^{\circ}-\mathrm{O}$ acesso ao ensino obrigatório e gratuito é direito público subjetivo.

$\S 2^{\circ}$ - O não-oferecimento do ensino obrigatório pelo Poder Público, ou sua oferta irregular, importa responsabilidade da autoridade competente. (BRASIL, 1988).

Sublinhamos que, embora os direitos sociais e, mais especificamente, o direito à educação sejam garantidos nas Constituições, isso não significa que automaticamente a população goze plenamente deles. Segundo Bobbio (1992), na sociedade contemporânea têm-se consagrado, nas normas legais, os diversos direitos sociais do homem; o problema é garantir as condições para o seu cumprimento.

Horta (1998) realça que os direitos sociais são muito mais difíceis de serem protegidos do que os direitos civis e políticos, porque, à medida que o número de proteções sociais aumenta, é mais complexa a sua satisfação. Uma forma de contribuir com a proteção dos direitos sociais é defini-los como direitos públicos subjetivos. Essa medida no Brasil foi defendida desde os anos 1930 (HORTA, 1998), mas só foi consagrada na Constituição de 1988.

O direito público subjetivo é a possibilidade que tem o cidadão de exigir, da administração pública, o cumprimento da oferta ou da prestação de serviços públicos e direitos previstos na legislação. A seguir, ressaltamos o conceito de direito público 
subjetivo que a Constituição de 1988 introduz como instrumento jurídico para firmar o direito à educação:

O direito público subjetivo configura-se como um instrumento jurídico de controle da atuação do poder estatal, pois permite ao seu titular constranger judicialmente o Estado a executar o que deve. De fato, a partir do desenvolvimento deste conceito, passou- se a reconhecer situações jurídicas em que o Poder Público tem o dever de dar, fazer ou não fazer algo em benefício de um particular (DUARTE, 2004, p. 113).

Sintetizando, historicamente a educação tem sido valioso instrumento de socialização, de preservação das tradições, bem como de mudanças sociais. Porém, o reconhecimento da educação como um direito social de todos os cidadãos e dever do Estado, expresso na legislação internacional, apareceu somente ao final do século XIX e início do século XX. O Brasil incorporou lentamente esse princípio, que foi incluído na maioria das Constituições promulgadas durante o século XX.

A sociedade civil organizada luta pela materialização desses direitos, mediante normas legais que regulem a sua prestação. A sua concretização, não obstante, está condicionada pelas opções políticas dos governantes com vistas a garantir os direitos sociais historicamente consagrados, bem como pelas possibilidades econômicas dos países. Nem sempre o Estado cumpre com a efetivação e a garantia plena dos direitos sociais, dado que deve responder às demandas da economia capitalista, que lhe exige diminuir os efeitos negativos causados pelas diversas crises econômicas, mediante políticas de ajuste e de reforma fiscal, com vistas à manutenção do processo de acumulação do capital.

\title{
Alcances e limites das políticas sociais
}

Como foi expresso anteriormente, a educação é considera como uma política pública de corte social, portanto é um conjunto de ações coletivas e focalizadas para materializar o direito à educação da cidadania. Entende-se por política pública o espaço de tomada de decisão autorizado ou sancionado por intermédio de atores governamentais, compreendendo atos que viabilizam agendas de inovação em políticas ou que respondem a demandas de grupos de interesses (COSTA, 1998).

Azevedo (1997, p. 5) menciona dois conceitos significativos no tocante à relação entre educação e políticas sociais:

\begin{abstract}
Abordar a educação como uma política social requer diluí-la na sua inserção mais ampla: o espaço teórico-analítico próprio das políticas públicas, que representam a materialidade da intervenção do Estado, ou o "Estado em ação".

Sendo assim, quando se enfocam as políticas públicas em um plano mais geral e, portanto, mais abstrato isto significa ter presente nas estruturas de poder e de dominação os conflitos infiltrados por todo o tecido social e que têm no Estado o lócus da sua condensação, como sugeriu POULANTZAS (1980). Em um plano mais concreto, o conceito de políticas públicas implica considerar os recursos de poder que operam na sua definição e que tem nas instituições do Estado, sobretudo na máquina governamental, o seu principal referente.
\end{abstract}

Portanto, devemos entender as políticas públicas, entre elas a educação, como arranjos institucionais em que comunidades de especialistas contribuem para a definição de 
determinadas agendas de políticas específicas, recortando a forma de representação de interesses e o desenvolvimento da ação governamental. É evidente que, na definição das políticas públicas, se estabelecem relações de poder, interesses e projetos societários dos diferentes segmentos da sociedade que se expressam de forma contraditória. Desse modo, as relações entre os interesses organizados são determinadas pela característica da política em questão, o que implica que cada política específica cria formas distintas de ação coletiva e repartição de recursos decisórios. (LOWI, 1964, p. 689, apud, COSTA, 1988).

Lowi afirma que as áreas de políticas ou de atividade governamental constituem 'arenas reais de poder'. Cada espaço ou arena de disputa pela hegemonia do controle do poder tenderia a desenvolver estruturas, processos políticos e relações entre grupos de interesses particulares e contrários que pretendem se impor no contexto da sociedade dividida em classes (COSTA, 1988).

Segundo Lowi (apud COSTA, 1988), a configuração de uma política é função direta das capacidades de unidade, associação e barganha entre indivíduos, grupos e associações de interesses, tendo como alvo as decisões nas agências governamentais.

A política social surge especificamente no contexto da sociedade capitalista, porque, segundo Saviani (1999, p. 1), esse tipo de organização social está centrado na “[...] propriedade privada dos meios de produção, o que implica a apropriação privada dos bens produzidos coletivamente". Em consequência, a classe social que detém o controle dos meios de produção se apropria da produção social da riqueza, como o Estado que, no contexto da sociedade capitalista, é uma instituição que regula as relações sociais de produção, mediante a política econômica, com vistas a consolidar a ordem capitalista, privilegiando, desse modo, os interesses privados sobre os interesses coletivos.

Assim, a política econômica pode ser vista como antissocial, pois mantém a ordem desigual própria da sociedade capitalista dividida em classes. Com o objetivo de equilibrar esses efeitos negativos no âmbito do Estado, elaboram-se as políticas sociais, que envolvem as áreas de saúde, previdência, cultura, comunicações, assistência social e educação. (SAVIANI, 1999). As políticas sociais que o governo adota dependem da conjuntura econômica e política.

As políticas sociais têm como escopo reduzir as desigualdades produzidas pelo modo de produção capitalista. Essas políticas são mecanismos de proteção social implementados pelo Estado. As políticas sociais referem-se a ações que determinam o padrão de proteção social instalado pelo Estado, voltadas, em princípio, para a redistribuição dos benefícios sociais visando à diminuição das desigualdades estruturais produzidas pelo desenvolvimento socioeconômico. "As políticas sociais têm suas raízes nos movimentos populares do século XIX, vinculadas aos conflitos surgidos entre capital e trabalho, no desenvolvimento das primeiras revoluções industriais". (HÖFLING, 2001, p. $31)$.

\section{Conclusão}

A implantação das políticas sociais na América Latina ocorreu nas primeiras décadas do século XX. Elas foram legitimadas nas Constituições nacionais promulgadas no período. Surgiram precisamente no momento em que os países da região adotavam políticas de cunho social e de proteção dos trabalhadores, com vistas à reprodução da força de trabalho. Embora as estruturas de poder tenham sofrido mudanças e novos líderes políticos tenham emergido, a base material econômica e as formas de dominação capitalista se mantiveram. 
Nesta pesquisa, constatamos que o direito à educação foi reconhecido em praticamente todas as Constituições do século XX. A primeira Constituição a incluir em seu texto um capítulo específico para a educação foi a Constituição alemã de Weimar, em 1918. Entretanto, a Constituição mexicana de 1917 foi precursora na introdução dos direitos sociais.

Toda sociedade implementa políticas educativas com o intuito de atender às suas necessidades de transmissão de valores culturais, políticos e sociais, de acordo com o momento. Portanto, o tipo de educação que se oferece responde às demandas da sociedade; o objeto das políticas educativas é efetivar os direitos individuais e coletivos historicamente conquistados.

As políticas educativas são desenhadas e efetivadas de acordo com um projeto de sociedade e são coerentes com a ideologia que as sustenta. Ou seja, elas têm por finalidade a formação humana, conforme uma concepção ou teoria de educação definida. Essas políticas materializam alguns desses preceitos ideológicos e interferem na organização e gestão escolar, no sistema de ensino, assim como nas instituições escolares, com o propósito de concretizar o dito projeto.

Como assinalamos neste texto, a elaboração das políticas educativas emana das forças sociais que têm representatividade no aparelho do Estado, assim como no interior da máquina de governo. De acordo com Bianchetti (200, p. 88), o "[...] poder público promove estratégias de caráter político com o objetivo de desenvolver um determinado modelo social". A formulação, a implantação e a execução dessas políticas depende da correlação de forças das bases materiais e ideológicas, assim como da economia que condiciona seus resultados.

As políticas educativas seguem objetivos gerais definidos num espaço social contraditório e antagônico, e sintetizam as diversas forças presentes no âmbito do Estado. No contexto da sociedade capitalista, as políticas educativas são ações e estratégias determinadas ideológica e economicamente que os governos executam na esfera da educação escolar e afetam diversos aspectos, como currículos, formação e carreira docente, construção de prédios, produção de material didático, livros didáticos, entre outros.

A sociedade civil tem instituído diversos mecanismos para acompanhar e regular o cumprimento dos direitos sociais, mais especificamente, o direito à educação, mediante a promulgação de normas legais e entidades (conselhos sociais, associações, institutos, entre outros), que monitoram a sua prestação. No entanto, a sua concretização está condicionada pelas possibilidades econômicas dos países e pela correlação de forças políticas. Nem sempre o Estado cumpre com a garantia plena dos direitos sociais previstos na legislação, devido às diversas crises econômicas do século $\mathrm{XX}$, bem como ao avanço da ideologia neoliberal, que prega o esvaziamento do conteúdo social da ação estatal.

\section{Referências}

ALEMANHA. Constitución del Imperio (Reich) Alemán de 11 de agosto de 1919. In: Textos Constitucionales españoles y extranjeros. Editorial Athenaeum: Zaragoza, 1930. Disponível em: <http://www.unav.es/constitucional/Materiales/Constitucion\%20 de\%20Weimar\%20(1919).pdf >. Acesso em: 25 dez. 2015.

ARENAS MONSALVE, Gerardo. El derecho colombiano de la seguridad social. Bogotá: Legis, 2009. 
AZEVEDO, Janete M. Lins de. A educação como política pública. Campinas, SP: Autores Associados, 1997. - (Coleção polêmicas de nosso tempo; v. 56).

BIANCHETTI, Lucídio. Modelo Neoliberal e Políticas Educacionais. 3. ed. São Paulo:Cortez, 2001.

BOBBIO, Norberto; MATTEUCCI, Nicola; PASQINO, Gianfranco. Dicionário de Política. 5. ed. Brasília: Editora da Universidade de Brasília: São Paulo: Imprensa Oficial/Editora, 2000.

BOBBIO, Norberto. O conceito de Sociedade Civil. Rio de Janeiro: Editora Geral, 1982.

BRASIL. Constituição da República dos Estados Unidos do Brasil, de 16 de julho de 1934. Disponível em: <http://www.planalto.gov.br/ccivil_03/Constituicao/

Constitui\%C3\%A7ao34.htm>. Acesso em: 2 out, 2015.

BRASIL. Constituição da República Federativa do Brasil, 5 de outubro de 1988.

Disponível em: http://www.planalto.gov.br/ccivil_03/constituicao/

constitui\%C3\%A7ao.htm.>. Acesso em: 25 jan. 2016.

BRASIL. Constituição da República Federativa do Brasil, de 1967. Disponível em: http://wwwplanaltogovbr/ccivil_03/constituicao/Constitui\%C3\%A7ao67.htm.>. Acesso em: 25 jan. 2016.

BRASIL. Constituição dos Estados Unidos do Brasil, de 18 de setembro de 1946.

Disponível em: <http : / / www.plana 1 t o . go v. b r / c c i vi l_ 03 / c o n s t i t u i c a o /Constitui\%C3\%A7ao46.htm.>. Acesso em: 2 out, 2015.

CHAUÍ, Marilena. Convite a Filosofia, Editora Ática, 2003

COLOMBIA. Constitución Política de Colombia 1936. Disponível em: < http://banrepcultural.org/sites/default/files/ACTO_LEGISLATIVO_1_DE_1936.pdf>. Acesso em: 01 fev. 2015.

COLOMBIA. Constitución Política de Colombia 1991. Disponível em: < http://pdba.georgetown.edu/Constitutions/Colombia/colombia91.pdf> Acesso em: 01 fev. 2016.

CONDORCET, Marie-Jean-Antoine-Nicolas Caritat. Cinco memórias sobre la instrucción pública e otros escritos. Madrid: Edições Morata, 2001.

COSTA, Nilson do Rosário. Políticas Públicas, Justiça Distributiva e inovação. Saúde e Saneamento na Agenda Social. São Paulo: Editora Hucitec, 1998.

CURY, Carlos Roberto Jamil. A Educação como desafio na ordem jurídica. In: LOPES, E. M. T.; GREIVE, C.; FARIA FILHO, L. (org.). 500 anos de educação no Brasil. Belo Horizonte: Autêntica, 2000. 
DUARTE, Clarice Seixas. Direito público subjetivo e políticas educacionais. São Paulo Perspec. [online]. 2004 vol.18, $\mathrm{n}^{\circ}$ 2, pp. 113-118. Disponível em:

http://www.scielo.br/pdf/spp/v18n2/a12v18n2.pdf. Acesso em: 15 setembro 2015.

ELIZAGA, Raquel Sosa. Los códigos ocultos del Cardenismo. México: Plaza e

Valdez/Universidad Nacional Autónoma de México, 1996.

FAURÉ, Christine. Las Declaraciones de los Derechos Del Hombre de 1789. [Trad.Diana Sanchez y José Luis Nuñez Herrejon], México, Comisión Nacional deDerechos Humanos. 1996.

GONZÁLEZ, Luis. El liberalismo triunfante. In: Historia General de México. El Colegio de México. Centro de Estudios Históricos: México, 2007.

GRAMSCI, Antonio. Notas sobre Maquiavelo, sobre Política y sobre el Estado Moderno. Buenos Aires/Madrid: Edições Nueva Visión, 1980.

HART, John Mason. El México revolucionário: gestación y proceso de la Revolución Mexicana. México: Alianza Editorial Mexicana, 1990.

HÖFLING, Eloisa de Mattos. Estado e Políticas (Públicas) Sociais. Cad. CEDES, vol. 2, 1 $n^{\circ} 55$, Campinas, nov./2001.

HORTA, José Silvério Baia. Direito à Educação e obrigatoriedade escolar. Cadernos de Pesquisa. São Paulo, Fundação Carlos Chagas, nº 4, p. 5-34, jul. 1998.

IANNI, Octavio. A sociedade global. Rio de Janeiro: Civilização Brasileira, 1992.

MARSHALL, Thomas Humphrey. Cidadania, Classe Social e Status. Rio de Janeiro: Zahar, 1967.

MARX, Karl. Crítica da filosofia do direito de Hegel. São Paulo: Boitempo, 2005.

MASON, Hart, John. El México Revolucionario, Gestación y Proceso de la Revolución Mexicana, Alianza Editorial, México, 1997.

MEXICO. Constitución Política de los Estados Unidos Mexicanos. Diário Oficial, Tomo V, $4^{\text {a }}$ Época, Número 30 México, 1917. Disponível em: < http://www.diputados.gob.mx/LeyesBiblio/ref/cpeum/CPEUM_orig_05feb1917.pdf>. Acesso em: 12 dez. 2015.

LÓPEZ OLIVA, José O. La Constitución de Weimar y los derechos sociales. La influencia en el contexto constitucional y legal colombiano a la luz de los derechos sociales asistenciales a la seguridad social en salud. Prolegómenos - Derechos y Valores. Bogotá, D.C. Colombia - Volumen XIII - No. 26 - Julio - Diciembre 2010. Disponível em: <http://www.redalyc.org/pdf/876/87617274014.pdf> . Acesso em: 12 dez. 2015.

ONU. Declaração Universal dos Direitos Humanos. Adotada e Proclamada na Assembleia-Geral na sua Resolução 217a (III), de 10/12/48. 
SAVIANI, Dermeval. Da nova LDB ao novo plano nacional de educação: por uma outra política educacional. 2. ed. Campinas SP: Autores Associados, 1998.

SHIROMA, Eneida Oto; MORAES, Maria Célia M. de \& EVANGELISTA, Olinda. Política educacional. Rio de Janeiro: DP\&A Editora, 2002.

VENEZUELA. Constitución de los Estados Unidos de Venezuela 1936. Disponível em: $<$ http://www.cervantesvirtual.com/servlet/SirveObras/01482741567835946320035/p00000 01. htm\#I_1_>. Acesso em: 01 dez. 2015.

VENEZUELA. Constitución de Venezuela de 1961. Disponível em: <http://download.rincondelvago.com/constitucion-de-venezuela-de-1961>. Acesso em: 03 jan. 2016.

VENEZUELA. Constitución de la República Bolivariana de Venezuela 1999. Disponível em: https://docviewer.yandex.com/?url=ya-diskpublic\%3A\%2

F\%2FdUaaY\%2B6\%2FjmMSaxOjDYkND9hcunkYNC7h9vuIed3y20w\%3D\&name=Con stituci\%C3\%B3n\%20de\%20la\%20Rep\%C3\%BAblica\%20Bolivariana\%20de\%20Venezue la.pdf\&c=589bfa8b379d>. Acesso em $01 \mathrm{dez} .2015$.

Notas

1 Da Universidade Federal de Mato Grosso do Sul - UFMS Doutora em Filosofia e História da Educação, professora do Curso de Pedagogia e Programa de Pós-Graduação em Educação da UFMS-Centro de Ciências Humanas e Sociais, Campo Grande/MS.

2 Polis é um termo grego que faz referência à cidade. Significa comunidade organizada, constituída pelos cidadãos, ou seja, os homens livres e iguais nascidos na Cidade. (CHAUÍ, 2003).

${ }^{3}$ Porfírio Diaz ocupou a presidência em diversos períodos, situação que evidencia a instabilidade política: de 29 de novembro de 1876 até 06 de dezembro de 1876; de 18 de fevereiro de 1877 até 30 de novembro de 1880 e de $1^{\circ}$ de dezembro de 1884 até maio de 1911.

Recebido: Abril/2017.

Aprovado: Junho/2017. 